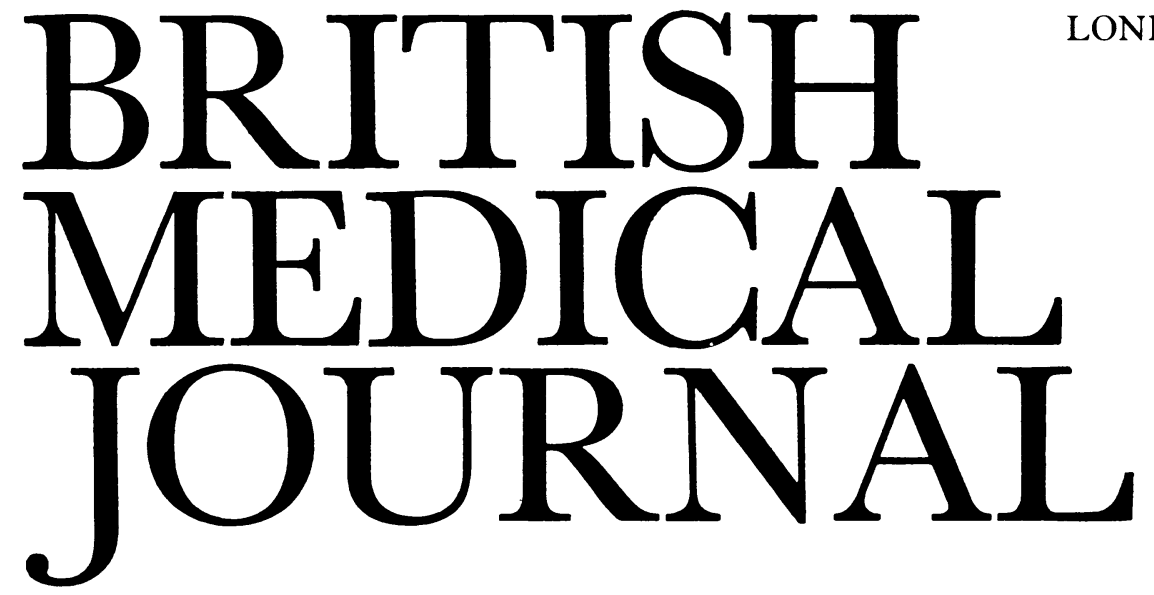

LONDON, SATURDAY 29 SEPTEMBER 1984

\title{
Where now for therapeutic apheresis?
}

Doctors, like other men, are creatures beguiled by fashion -so that every treatment has its day. The pattern is predictable: each new treatment provokes an initial wave of enthusiasm when it is applied to every possible disease, only for this to be followed by utter rejection and despondency when it is said to be good for nothing. Eventually, we hope, it finds its level: specific for this, useful for that, to be used in such and such when all else fails.

Therapeutic apheresis is now entering the slough of despond. While plasmapheresis had been in use for more than a decade in treating the hyperviscosity syndrome associated with macroglobulinaemia, ${ }^{1}$ its popularity really began to grow in 1976, when two British groups reported its successful use in separate immunologically mediated diseases, systemic lupus erythematosus ${ }^{2}$ and Goodpasture's syndrome. ${ }^{3}$ In the next seven years apheresis was tried in a further 143 diseases $^{45}$ with degrees of success ranging from the spectacular ${ }^{6}$ to the abysmal. ${ }^{7}$ Medical journals became so peppered with anecdotes that controlled trials were called for, and these became all the more urgent when the financial implications were considered. A report of the successful use of plasma exchange in rheumatoid arthritis ${ }^{8}$ spurred Verrier Jones to calculate that were this treatment to be offered to all patients with rheumatoid arthritis in the United States who might benefit from it, it would add $\$ 2$ billion to the United States health care budget. ${ }^{9}$ Not only that: 30 million blood donations a year would be required to supply the amount of albumin that would be needed as replacement fluid. If the report that disseminated cancer might regress with plasma exchange were confirmed, then the potential market for cell separators would know no bounds and most of us would have to set aside some considerable time every year as plasma donors. ${ }^{10}$

There have been controlled trials, however, with generally discouraging results. Thus in Guillain-Barré syndrome plasma exchange was no better than supportive care alone,${ }^{11}$ in multiple sclerosis plasma exchange and low dose cyclophosphamide were better than corticotrophin but worse than high dose cyclophosphamide, ${ }^{12}$ in Crohn's disease low dose steroids were as good as plasma exchange, ${ }^{13}$ in the long term management of myasthenia gravis plasma exchange added nothing to the beneit obtained with immunosuppressive drugs, ${ }^{14}$ and in both mild systemic lupus erythematosus ${ }^{15}$ and scleroderma ${ }^{16}$ plasma exchange produced the same benefit as a sham technique. Controlled trials are proceeding in thrombotic thrombocytopenic purpura, rhesus haemolytic disease of the newborn, and immune thrombocytopenia, ${ }^{17}$ but only in Raynaud's disease has plasma exchange proved to be better than other remedies, and even this trial was not controlled for the placebo effect..$^{18}$

Patients with rheumatoid arthritis are notoriously susceptible to placebos, and it would be difficult to design one more potent than connecting the patient by an array of plastic tubes to a complicated machine complete with bleepers and flashing lights. In an early study Wallace $e t$ al found that six out of eight patients entered a period of remission during the course of and after 20 exchanges over 11 weeks. ${ }^{8}$ In a controlled study, however, Rothwell et al found that plasmapheresis was no better than physiotherapy in a group of hospital patients. ${ }^{19}$ Finally, Dwosh et al, in a study that is hard to fault, showed that a group of patients with severe, unresponsive rheumatoid arthritis benefited no more from the replacement 10 times in four weeks of $40 \mathrm{ml}$ of their plasma per kg by human serum albumin than from the removal of the same amount of plasma at the same frequency followed by its surreptitious return to the patient under the guise of a plasma exchange. ${ }^{20}$

Does this mean that we can abandon plasma exchange as once before we abandoned bloodletting? Not at all. Though hardly more specific than bloodletting, apheresis is both safer and more powerful and capable of removing from the body any toxin located mainly within the blood stream. Perhaps the best example is the toxin of the poisonous mushroom Amanita phalloides, ${ }^{21}$ but several drugs as well as IgM are similarly distributed. Undoubtedly plasma exchange works well in such simple circumstances, and no controlled trial is necessary. We are dealing with simple arithmetic.

The assessment becomes slightly more complicated when a known toxin is distributed both within and outside the vasculature, with the two compartments in dynamic equilibrium. If the source of supply of fresh toxin can be interrupted (and provided that no irreversible harm has 
been done to the target organ) then again the removal of the toxin from the plasma in sufficient quantities will benefit the patient. A good example is Refsum's syndrome, where diet may be used to restrict the accumulation of phytanic acid and this may be supplemented by its removal from the plasma. ${ }^{22}$ Similarly, in Goodpasture's syndrome and myasthenia gravis the toxins are respectively antibodies against glomerular basement membrane and acetyl choline receptors, and immunosuppressive drugs may be used to diminish their production. ${ }^{23}$ In Goodpasture's syndrome survival and recovery of renal function after plasma exchange are so much better than in historical controls that it would take a brave (and perhaps a foolhardy) man to randomise such patients to an arm of a trial that did not include it. ${ }^{22}$ In severe and life threatening myasthenia gravis the known delay in the action of immunosuppressive drugs may be circumvented by plasma exchange, and during this period alone it is clearly indicated. ${ }^{14}$

The success of plasma exchange in these antibody mediated diseases is no warrant for its use in others. In most, immunosuppressive drugs will suffice; and if they cannot be given then physiological principle ${ }^{24}$ and practical experience ${ }^{25}$ dictate that the antibody will rebound to former or even higher concentrations. Alloantibodies may behave differently from autoantibodies. Thus if antirhesus antibodies are not restimulated during pregnancy (as, for example, by amniocentesis) then plasma exchange will lower their concentrations to the benefit of the baby. ${ }^{26}$

Diseases mediated by immune complexes are more complicated. One clear cut effect of plasma exchange is to lift the blockade imposed by circulating complexes on their clearance by the reticuloendothelial system. ${ }^{27} 28 \mathrm{~A}$ more theoretical prospect is that plasma exchange may modulate the immune response by influencing the composition of the complexes and their distribution between body compartments. ${ }^{29}$ Impressive responses to plasma exchange have been reported in uncontrolled studies of rapidly progressive glomerulonephritis, ${ }^{30}$ acute systemic lupus erythematosus, ${ }^{31}$ and rheumatoid vasculitis, ${ }^{32}$ but there have been no satisfactory controlled studies. Nor are these easy to organise. The diseases are rare, action is often urgent, and protocols may often prove inappropriate. Moreover, controlled trials can test only the particular schedules that they examine, and when these must be determined without sufficient knowledge of underlying pathogenic mechanisms interpretation of the results must be difficult. The case for plasma exchange in immune complex disease is not proved, and more patients are urgently needed for well designed trials such as Professor Kater's for lupus nephritis. ${ }^{33}$

The physical removal of lymphocytes from the body modulates the immune response. In 1977 Paulus et al reported clinical improvement in patients with drug resistant rheumatoid arthritis treated by drainage of the thoracic duct. ${ }^{34}$ They removed $5 \times 10^{10}$ lymphocytes daily -10 times as many as in the most intensive studies of lymphocytapheresis in rheumatoid arthritis. Nevertheless, Tenenbaum et al showed clinical benefit from removing between 0.2 and $4.5 \times 10^{9}$ lymphocytes daily over 19 days in two patients ${ }^{35}$; Wallace $e t$ al reported that of four patients from whom $5 \times 10^{9}$ lymphocytes plus three litres of plasma were removed on 20 occasions, all went into remission. ${ }^{9}$ Karsh et al showed a 60\% improvement in the Ritchie index of four patients by removing $1 \cdot 1 \times 10^{10}$ lymphocytes over six weeks $s^{36}$ and then sought to confirm it by a randomised double blind trial controlled by a sham procedure. ${ }^{37}$ In this study the control group did not experience a placebo effect, and, though the treated group showed a benefit, it was not great-indeed no better than has frequently been achieved by placebos. A double blind controlled trial of lymphoplasmapheresis versus sham apheresis by Wallace et al removed $40 \mathrm{ml}$ plasma per $\mathrm{kg}$ and $5 \times 10^{\circ}$ lymphocytes nine times in three weeks. ${ }^{38}$ Both the treated group and the sham group improved. The difference between the real and spurious treatment was significant when assessed by the nurse (who knew what was going on) but not when assessed blindly by the doctor. Verdickt et al compared removal of $345 \mathrm{ml}$ plasma per $\mathrm{kg}$ together with $5 \times 10^{9}$ lymphocytes six times in three weeks with a sham procedure on a double blind basis. ${ }^{39}$ The improvement in laboratory indices was not reflected in clinical benefit. As yet neither lymphocytapheresis nor lymphocytoplasmapheresis has found a place in this or any other immunologically mediated disease.

TERRY HAMBLIN

Consultant Haematologist,

Royal Victoria Hospital,

Bournemouth BH1 4JG

1 Solomon A, Fahey JC. Plasmapheresis therapy in macroglobulinemia. Ann Intern Med 1963;58:789-800.

Jones JV, Cumming RH, Bucknall RC, et al. Plasmapheresis in the management of acute systemic lupus erythematosus. Lancel 1976; i: $709-11$

Lockwood CM, Rees AJ, Pearson TA, Evans DJ, Peters DK, Wilson CB. Immunosuppression and plasma exchange in the treatment of Goodpasture's syndrome. Lancet 1976;i:711-5.

Hamblin TJ. Update on plasmapheresis. Apheresis Bulletin 1983;1:10-7.

6 Dau PC, Kahaleh MB, Sagebiel RW. Plasmapheresis and immunosuppressive drug therapy in scleroderma. Arthritis Rheum 1981;24:1128-36.

Power D, Nicholas A, Muirhead N, et al. Plasma exchange in acute allograft rejection-is a controlled trial really necessary? Transplantation 1981;32:162-3.

8 Wallace DJ, Goldfinger D, Gatti R, et al. Plasmapheresis and lymphoplasmapheresis in the management of rheumatoid arthritis. Arthritis Rheum 1979;22:703-19.

9 Jones JV. Plasma exchange and lymphocytapheresis in rheumatoid arthritis. Apheresis Bulletin 1983;1:152-7.

0 Israel L, Edelstein R, Mannoni P, Radot E. Plasmapheresis and immunological control of cancer. Lancet $1976 ; \mathrm{i}: 642-3$.

11 Greenwood RJ, Newsom-Davis J, Hughes RAC, et al. Controlled trial of plasma exchange in acute inflammatory polyradiculoneuropathy. Lancet 1984; i:877-9.

2 Hauser SL, Dawson DM, Lehrich JR, et al. Intensive immunosuppression in progressive multiple sclerosis: a randomised three arm study of high dose cyclophosphamide, plasm exchin

Hamblin T, Holdstock G, Fisher A, Loehry C. Plasma exchange in Crohn's disease. In: Sieberth 1981:309-14. 4 Newsom-Davis, Wilson SG, Vincent A, Ward CD.

exchange in myasthenia gravis. Lancet 1979;i:464-8.
Wei N, Klippel JH, Huston DP, et al. Randomised trial of plasma exchange in mild systemic

16 McCune MA, Winkelmann RK, Osmundson PJ, Pineda AA. Plasma exchange: a controlled study of the effect in patients with Raynaud's phenomenon and scleroderma. Fournal of Clinical Apheresis 1983;1:206-14.

17 Rock G. The Canadian experience of plasma exchange. Apheresis Bulletin 1983;1:84-6

8 O'Reilly MJG, Talpos G, Roberts VC, White JM, Cotton LT. Controlled trial of plasma exchange in the treatment of Raynaud's syndrome. Br Med $\mathcal{F}$ 1979;i:113-5.

Rockwell RS, Davis P, Gordon PA, et al. A controlled study of plasma exchange in the treatment of severe rheumatoid arthritis. Arthritis Rheum 1980;25:785-90. Dwosh TL, Giles AR, Ford PM, Pater JL, Anastassiades TP. Plasmapheresis therapy in
rheumatoid arthritis: a controlled double blind crossover trial. $N$ Engl $\mathcal{J}$ Med 1983;308:
$1124-9$.

21 Mercuriali F, Sirchia G. Plasma exchange for mushroom poisoning. Transfusion 1977; 17:644-6. 2 Gibberd FB, Billimonia JD, Page NUR, Retsas S. Heredopathia atactica polyneuritiformis (Refsum's disease) treated by diet and plasma exchange. Lancet 1979;i:575-8.

23 Peters DK, Rees AJ, Lockwood CM, Pusey CD. Treatment and prognosis in anti-basement membrane antibody mediated nephritis. Transplant Proc 1982;14:513-21.

4 Bystryn JC, Graf MW, Uhr JW. Regulation of antibody formation by serum antibody. $\mathcal{F}$ Exp Med 1970;132:1279-87.

25 Branda RF. Antibody production in Goodpasture's syndrome. Lancet 1976;i:1134.

26 Robinson EAE, Tovey LAD. Intensive plasma exchange in the management of severe Rh disease. Br F Haematol 1980;45:621-31.

Frank MM, Hamburger M, Lawley TS, Kimberley RP, Plotz PH. Defective reticuloendothelial system Fc receptor function in systemic lupus erythematosus. N Engl I Med 1979;300:518-23. Lockwood CM, Worledge S, Nicholas A, Cotton C, Peters DK. Reversal of impaired solenic functions in patients
$1979 ; 300: 524-30$

29 Bystryn JC, Shenkein I, Uhr JW. A model for the regulation of antibody synthesis by serum antibody. Progress in Immunology 1971;1:627-36.

Lockwood CM, Rees AJ, Pinching AJ, et al. Plasma exchange and immunosuppression in the treatment of fulminating immune complex crescentic glomerulonephritis. Lancet 1977; i: 63-7. Jones JV, Robinson MF, Parciany RK, Layfer LF, McLeod B. Therapeutic plasmapheresis in systemic lupus erythematosus. Effect on immune complexes and antibodies to DNA. Arthritis Rheum 1981;24:1113-20.

32 Scott DGI. The role of plasma exchange in rheumatoid vasculitis. Plasma Therapy 1983;4:253-

70.
Kater L. Protocol to study plasma exchange in the treatment of systemic lupus erythematosus. Plasma Therapy 1983;4:331

Paulus HE, Machleder HI, Levine S, Yu DTY, MacDonald NS. Lymphocyte involvement in rheumatoid arthritis, studies during thoracic duct drainage. Arthritis Rheum 1977;20:1249-62. Tenenbaum J, Urowitz MB, Keystone EC, Dwosh

rheumatoid arthritis. Ann Rheum Dis 1979;38:40-4. by continuous flow cell centrifugation in rheumatoid arrhritis. Arthritis Rheum depletion $1055-9$.

37 Karsh J, Klippel JH, Plotz PH, Decker JL, Wright DG, Flye MN. Lymphapheresis in rheumatoid arthritis. A randomised trial. Arthritis Rheum 1981;24:867-73.

Wallace D, Goldfinger D, Lowe C, et al. A double blind controlled study of lymphoplasma pheresis versus sham apheresis in rheumatoid arthritis. $N$ Engl f Med 1982;308:1408-10.

9 Verdickt W, Dequeker J, Cueppens JL, Stevens E, Gautama K, Veringlen C. Effect of lymphoplasmapheresis on clinical indices and $\mathrm{T}$ cell subsets in rheumatoid arthritis. Arthritis
Rheum 1983;26:1419-26. 